\title{
Educação do campo na UEMA: uma análise da linha de pesquisa prática pedagógica nos Trabalhos de Conclusão do Curso na modalidade a distância
}

\section{Campus education at UEMA: an analysis of the pedagogical practice research line in distance learning Course Completion Assignments}

DOI: $10.46814 /$ lajdv3n5-031

Recebimento dos originais: 01/05/2021

Aceitação para publicação: 31/06/2021

Ilma do Socorro Santana Pinheiro

Mestra em História, Ensino e Narrativas - Universidade Estadual do Maranhão - UEMA

Departamento UEMAnet/UEMA. Cidade Universitária Paulo VI - Caixa Postal 09 -Av. Lourenço

Vieira da Silva, No 1000 - Jardim São Cristóvão - São Luís/MA, CEP: 65.055-310.

E-mail: ilma.pinheiro@uemanet.uema.br

\section{Eliza Flora Muniz Araújo}

Mestra em Ciências da Educação - Universidade da Madeira - Funchal, Portugal

Departamento UEMAnet/UEMA. Cidade Universitária Paulo VI - Caixa Postal 09 -Av. Lourenço

Vieira da Silva, No 1000 - Jardim São Cristóvão - São Luís/MA, CEP: 65.055-310.

E-mail: eliza.araujo@uemanet.uema.br

\section{Ilka Márcia Ribeiro de Souza Serra}

Doutora em Fitopatologia - Universidade Federal Rural de Pernambuco - UFRPE

Departamento UEMAnet/UEMA. Cidade Universitária Paulo VI - Caixa Postal 09 -Av. Lourenço

Vieira da Silva, No 1000 - Jardim São Cristóvão - São Luís/MA, CEP: 65.055-310.

E-mail: ilka.serra@uemanet.uema.br

\begin{abstract}
RESUMO
O presente artigo versa sobre as linhas de pesquisa abordadas pelos alunos do Curso de Especialização em Educação do Campo a distância no Trabalho de Conclusão de Curso-TCC, tendo como foco a prática docente e estabelecendo uma relação com a teoria estudada no decorrer do curso. Propõe analisar o quantitativo de alunos por linha de pesquisa, investigando, especificamente, a temática "Prática Pedagógica em Educação do Campo" na perspectiva de observar a preocupação dos sujeitos que estão inseridos no Curso de Especialização em Educação do Campo, tendo como referência a vivência em suas comunidades. Trata-se de um estudo bibliográfico sobre a educação do campo, e, nesse contexto, sobre o perfil do professor a distância, bem como o perfil do professor orientador, abordando os resultados dos Trabalhos de Conclusão de Curso, cujos resultados possibilitaram perceber que a prática docente tem relação direta com o ambiente de aprendizagem no qual o aluno encontra-se inserido. O estudo foi realizado no Ambiente Virtual de Aprendizagem - AVA tomando como referência os artigos postados na sala de Elaboração e Orientações do TCC em cada linha de pesquisa. O resultado do estudo trouxe a evidência de que os artigos produzidos pelos alunos são de grande relevância tanto para os professores cursistas quanto para a comunidade acadêmica, vez que socializam o que foi produzido e possibilitam a reconstrução dos espaços de relação que fortalecem as raízes da população campesina, oportunizando, assim, novos aprendizados a alunos e professores no que se refere ao uso das novas tecnologias e aos saberes mais específicos da educação do campo.
\end{abstract}

Palavras-chave: Educação do campo. Prática pedagógica. EAD. 


\begin{abstract}
This paper discusses the research lines worked by students from the Specialization Field Education distance as completion of course work focusing on teaching practice establishing a relation with the studied throughout the course theory. Proposes to examine the quantity of students per research area, specifically investigating the Thematic Teaching Practice in Rural Education in the perspective of observing the concern of the subjects entered with reference to experience in your community. This is a bibliographic study on rural education, and in this context the teacher profile distance as well as the profile of the teacher advisor, addressing the results of the work of completing the course, the results of which enabled realize that teaching practice has directly related to the learning environment in which the student is inserted. The study was conducted in the Virtual Learning Environment - VLE reference to the articles posted on the Development and the CBD Guidelines room in each line of research. The results of the study provided evidence that the articles produced by the students are of great importance both for the participant teachers as the academic community since socializes what was produced and allows the reconstruction of the areas of relationship that strengthen the roots of the peasant population , thus providing opportunities, new learning for students and teachers both in regard to the use of new technologies as the more specific knowledge of the field of education.
\end{abstract}

Keywords: rural education. pedagogical practice. EAD.

\title{
1 INTRODUÇÃO
}

Neste artigo, apresentam-se as linhas de pesquisas abordadas pelos alunos do Curso de Especialização em Educação do Campo, na modalidade a distância, no Trabalho de Conclusão de Curso- TCC. Ao combinar os estudos sobre saberes do campo com a tecnologia educacional, suscitouse uma discussão em defesa do perfil do professor orientador e dos avanços da prática pedagógica, na expectativa de ampliar os conhecimentos sobre o uso didático das novas tecnologias como ferramentas auxiliares do professor tutor, tendo em vista que, na $\mathrm{EaD}$, este assume o papel de mediador do processo de ensino-aprendizagem.

Os alunos da Especialização são professores que já atuam ou atuaram nas escolas rurais, bem como do campo e que procuram aperfeiçoar-se para uma melhor compreensão acerca das temáticas relacionadas à Educação do Campo para dessarte, fortalecerem a sua prática cotidiana. Ao se observar o diálogo da prática pedagógica com a teoria estudada nas disciplinas existentes na matriz curricular do curso, a ação docente surge como temática de maior relevância nos TCCs.

Assim sendo, neste estudo, buscou-se analisar o quantitativo de alunos por linha de pesquisa e caracterizar a amostra relacionada à prática pedagógica, encontrando-se um contexto de amplos debates no que tange às ações pedagógicas, o que corroborou com a metodologia qualitativa, pois possibilitou responder a algumas questões inerentes às especificidades e experiências dos sujeitos envolvidos.

A pesquisa se pautou na apreciação de material bibliográfico, assim como na seleção de artigos postados na sala de Elaboração e Orientações do TCC, no Ambiente Virtual de Aprendizagem- AVA 
Moodle do referido curso, em cada linha de pesquisa, sendo analisados 728 artigos no período de 10 a 28 de fevereiro de 2014. Ademais, tratou-se de uma pesquisa de natureza quantitativa e qualitativa: quantitativa, porque procurou enumerar e/ou medir os eventos estudados e empregou instrumental estatístico na análise dos dados; qualitativa, porque se baseou na obtenção de informações descritivas sobre a linha de pesquisa "Prática Pedagógica", fazendo uma relação de análise reflexiva dos resultados obtidos mediante as pesquisas científicas dos alunos. Segundo Minayo (2007, p. 22), “A pesquisa qualitativa se aprofunda no mundo dos significados. Todavia esse nível de realidade não é visível, precisa ser exposta e interpretada, em primeira instância, pelos próprios pesquisados." Portanto, trabalhou-se utilizando tanto os dados quantitativos quanto os qualitativos na perspectiva de uma melhor investigação da problemática em questão.

O Curso foi realizado no período de 2010 a 2011 e, por ser na modalidade a distância, teve a mediação do Núcleo de Tecnologias para Educação - UEMAnet da Universidade Estadual do Maranhão - UEMA, com encontros presenciais para as orientações in loco.

Nesse sentido, vale referenciar novamente Minayo quando a autora destaca que o debate entre as abordagens quantitativas e qualitativas da realidade social não se refere a uma questão hierárquica, mas sim de natureza. Para ela, os dois tipos de abordagens e as informações produzidas não são incompatíveis, pois podem se completar, contudo enfatiza haver muitas controvérsias sobre essa questão.

É importante registrar que, para que a análise dos artigos acontecesse, houve a autorização dos autores, os quais prestaram alguns esclarecimentos e ajudaram a compreender melhor o desenvolvimento da pesquisa e o nosso papel enquanto pesquisadores. Essas contribuições foram de grande relevância para o estudo, vez que o processo de produção do conhecimento não se limitou apenas aos registros, mas também aos relatos dos participantes.

\section{EDUCAÇÃO DO CAMPO E A EAD}

A Educação do Campo nasceu como mobilização/pressão de movimentos sociais por uma política educacional direcionada às comunidades camponesas, especificamente, surgiu da combinação das lutas do Movimento dos Trabalhadores Rurais Sem Terra pela implantação de escolas públicas nas áreas de Reforma Agrária com as de resistência de inúmeras organizações e comunidades camponesas para que suas escolas, suas experiências de educação, suas comunidades, seu território e suas identidades não fossem perdidos.

Assim, os sujeitos do campo têm direito a um estudo de qualidade quando não têm acesso aos estudos nos horários estabelecidos pelas instituições, pois a educação a distância é voltada, sobretudo, mas não exclusivamente, para adultos que, em geral, já estão no mundo coorporativo e não dispõem 
de tempo suficiente para estudar na modalidade presencial. À vista disso, vale mencionar a Constituição Federal, conforme citado por Soares (2001):

[...] pode-se afirmar que proclama a educação como direito de todos e dever do Estado, transformando-a em direito público subjetivo, independentemente dos cidadãos residirem nas áreas urbanas ou rurais. Deste modo, os princípios e preceitos constitucionais da educação abrangem todos os níveis e modalidades de ensino ministradas em qualquer parte do país (SOARES, 2001, p. 10).

Observa-se, então, que a Educação do Campo oportuniza o estudo de forma presencial e a distância, sendo essa última uma modalidade que completa a formação básica ou mesmo que realiza novos cursos de aperfeiçoamento dos conhecimentos já adquiridos. Além disso, propicia a aprendizagem por meio de novas experiências acadêmicas, e esse fato se dá pelo direito que assiste aos sujeitos que vivem no campo e na zona rural.

Segundo Kolling, Nery e Molina (1999, pp. 93-94), a Educação do Campo, mediante práticas e estudos científicos, deve aprofundar uma pedagogia que respeite a cultura e a identidade, tempos, ciclos da natureza, mística da terra, valorização do trabalho, festas populares e outros aspectos que permeiam a vida dos povos do campo. Vale ressaltar que essa cultura de identidade também se insere na educação a distância, visto que esta se destina às pessoas que não têm condições de participar do sistema presencial, cujos mecanismos adotados possibilitam uma aprendizagem ativa e autônoma, na qual os cursistas possuem flexibilidade para a participação das atividades e fóruns interativamente por meio das Tecnologias da Informação e Comunicação - TICs. Portanto, a oferta da Especialização aos professores das escolas do campo vem reforçar a necessidade de que sejam incentivadas estratégias inovadoras de formação voltadas a essas categorias de profissionais, que, pelo sistema presencial, dificilmente teriam condições de participarem de um processo de formação no qual seriam capazes de reverem e aperfeiçoarem suas práticas, bem como seriam incluídos digitalmente.

Muito mais que discutir direitos e deveres dos professores da escola do campo, a cidadania deve ser compreendida enquanto ação de resgate de identidade de seus sujeitos que, por muito tempo, ficaram esquecidos em suas práticas sociais. Segundo Araújo (2010):

[...] há de pensar na construção de uma escola rural sintonizada com o seu tempo, que tenha como perspectiva a superação dos desafios e contradições. Considerar também, que nas sociedades modernas a educação se constitui um dos instrumentos mais importantes para o enfrentamento das desigualdades sociais, para a conquista dos valores democráticos e para a melhoria das condições de vida de sua gente. (ARAÚJO, 2010, p. 154).

Esse pensamento corrobora as ideias contidas no documento da Conferência Nacional de Educação- CONAE (2010, p.81), que enfatiza a relevância de assegurar o desenvolvimento de 
competências e habilidades para o uso das TICs na formação inicial e continuada dos/das profissionais da educação, na perspectiva de transformação da prática pedagógica e da ampliação do capital cultural dos/das professores/as e estudantes.

\section{O PAPEL DO PROFESSOR ORIENTADOR}

O professor orientador na EaD é o mediador dos processos de ensino- aprendizagem no que concerne às orientações dos trabalhos. O professor tutor, segundo Andrade:

Deve ser visto como um professor à distância, com um papel similar ao professor do ensino presencial, sendo ele responsável por promover a interatividade, pela troca de experiência entre os alunos e por reforçar a comunicação do grupo (ANDRADE, 2009, p. 04).

De acordo com o pensamento acima, o papel desse profissional é de suma importância no desenvolvimento do conhecimento, assim como no processo de interação com os alunos para que possam obter resultados positivos, haja vista que ele deve ser claro ao estabelecer as expectativas de participação nas atividades e, também, ao orientar os participantes.

Para Harasim et al. (2005, p. 221), "as redes de aprendizagem proporcionam uma rica oportunidade de intercâmbio de informações e ideais, em que todos os alunos podem participar ativamente, aprendendo uns com os outros e com os professores”. Dessa forma, a comunicação mediada pelo computador oferece aos educadores oportunidades e desafios únicos, e o professor, enquanto indivíduo no processo de organização de sua formação, amplia o campo de experiências profissionais ao preparar os estudantes para as mudanças. Essa ideia vai ao encontro do que aponta Alves (1991, p.37):

O professor traz para o processo de formação profissional, a sua experiência passada, o seu conhecimento, as obrigações atuais e as aspirações para o futuro, que influenciarão decisivamente a sua aprendizagem. Negar isto significa negar a instrução dada na formação inicial e os esforços dos educadores quando um curriculum foi preparado para formar professores.

De acordo com Sacristán, a competência do professor não se constitui somente técnica composta por um conjunto de treinos que se desenvolvem com base em conhecimentos concretos ou na experiência, tampouco descoberta pessoal. "O papel do professor não é técnico, de um profissional que improvisa, mas de um profissional que deve tirar proveito do seu potencial teórico e de seus aprendizados para se desenvolver em contextos pedagógicos práticos preexistentes”. (SACRISTÁN, 1999, p.74). 
Nessa mesma perspectiva, Tardif destaca que o saber do professor não se limita à prática apenas, mas também precisa de sustentação das teorias educacionais. Assim sendo, os conhecimentos teóricos tornam-se imprescindíveis no processo de formação dos professores, uma vez que possibilita diferentes visões aos sujeitos para que estes tenham atuação mais contextualizada, perspectivas de análises, permitindo, assim, a compreensão dos contextos históricos, sociais, culturais, organizacionais e de si próprios enquanto profissionais. (TARDIF, 2000, p.24).

O Curso de Especialização em Educação do Campo seguiu nessa mesma direção, ou seja, dentro da linha de pesquisa "Prática Pedagógica", objeto deste estudo, tendo os alunos definido suas temáticas com base nas vivências práticas, a partir das teorias apreendidas durante o curso, e exercitando o diálogo entre teoria e prática.

\section{AS LINHAS DE PESQUISAS PARA O TRABALHO DE CONCLUSÃO DE CURSO}

Em princípio, a pesquisa se constitui um instrumento de ensino e conteúdo de aprendizagem na formação dos professores, notadamente, para a análise dos contextos em que se inserem as situações cotidianas da escola, para a construção de conhecimentos que ela demanda e para a compreensão da própria tarefa de ensinar. Essa ideia encontra respaldo nas Propostas de Diretrizes para a Formação Inicial de Professores da Educação Básica do MEC:

É importante que os futuros professores tenham noções básicas dos contextos e dos métodos de investigação usados pelas diferentes ciências, para que não se tornem meros repassadores de informação [...] e que tenham acesso aos conhecimentos produzidos pela investigação acadêmica. (BRASIL, 2001, p. 19).

As orientações sobre as linhas de pesquisa a serem desenvolvidas foram apresentadas aos alunos pela Coordenação do Curso de acordo com as disciplinas estudadas no decorrer do curso e com as práticas vivenciadas pelos cursistas no exercício de suas funções em cada município. Mediante a isso, surgiu a necessidade da criação de uma sala específica no AVAMoodle para facilitar as orientações e postagens dos artigos. Esse espaço foi de grande relevância para o aprendizado e, desse modo, facilitou o processo de comunicação entre a Coordenação, tutores e alunos, vez que continha informações e materiais de cada linha de pesquisa, conforme demonstra a figura a seguir: 
Figura 1: Print do banner da sala de Elaboração e Orientações do TCC
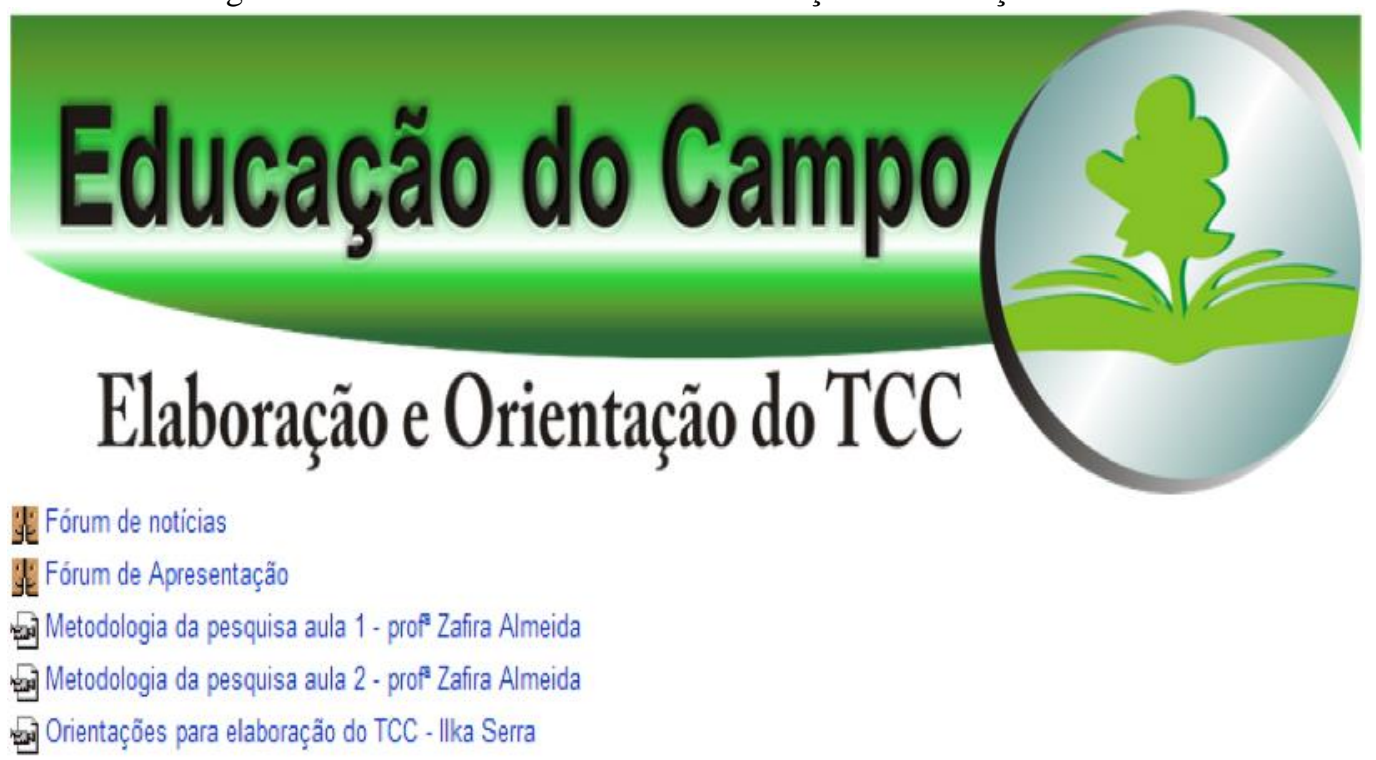

Os professores realizaram as orientações em dois momentos, a saber: a distância, por meio da sala criada com vistas à obtenção de conhecimentos e orientações; e presencial - nos polos, visando à organização do acervo científico e metodológico necessário para a elaboração dos artigos. Essa ação vai ao encontro da ideia de que a produção científica, cultural e artística exige a possibilidade de reflexão não ligada imediatamente à produção e a resultados concretos. Um ambiente intelectualmente adequado, um meio apto à produção de conhecimento, não pode estar condicionado pelo imediatismo de lógicas produtivas. (VIGEVANE, 2001).

Vásquez (1977, p. 207) aborda esta questão: “A teoria em si não transforma o mundo. Pode contribuir para as novas transformações, mas para isso tem que sair de si mesma, e em não ocasionar, com seus atos reais efetivos, tal transformação".

Foi com base nessa concepção que a UEMA tomou a iniciativa de publicar os artigos nas quatro linhas de pesquisa contidas no Caderno de Artigos Científicos, constituído de dois volumes: Volume 1: Educação do Campo e a Educação a Distância; e Gestão Educacional. Volume 2: Movimentos Sociais e Reforma Agrária; e Práticas Pedagógicas.

Os referidos cadernos foram enviados aos polos, bem como distribuídos para os alunos e tutores presenciais e a distância na perspectiva de disseminar e incentivar outros profissionais ao desenvolvimento de pesquisas. 
Figura 2: Volume 1 - Educação do Campo

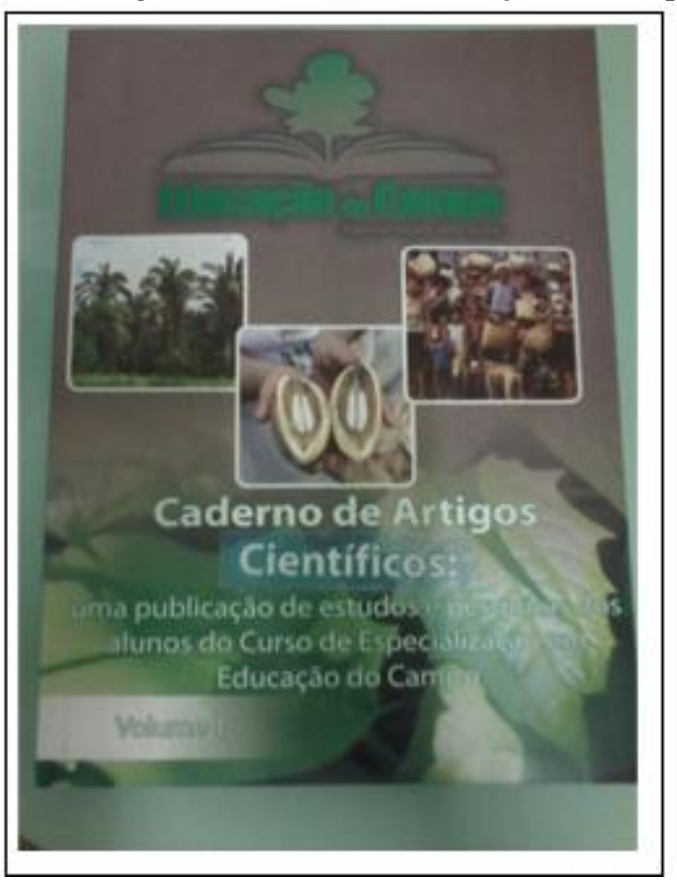

Figura 3: Volume 2 - Educação do Campo

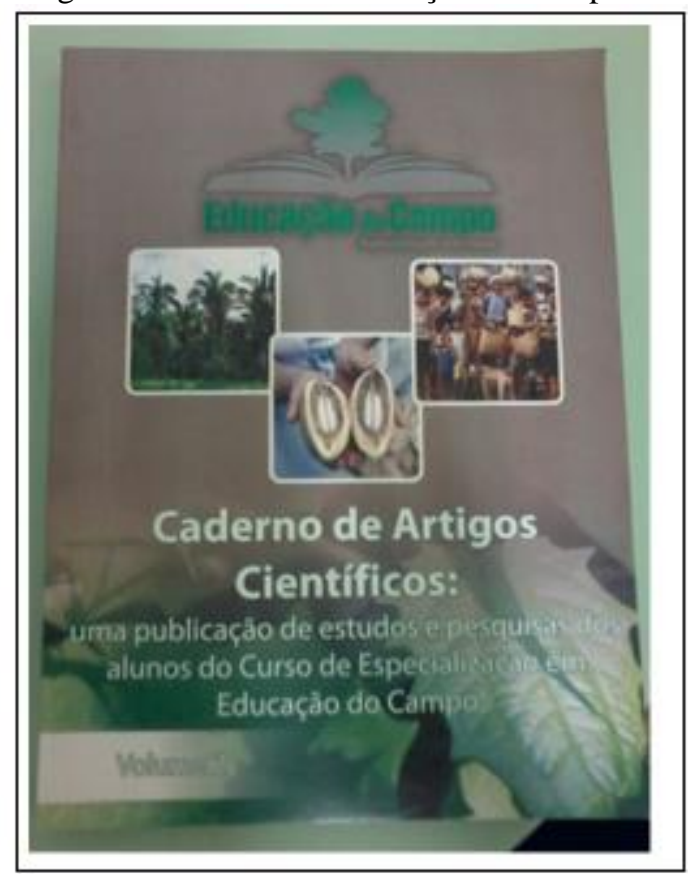

No contexto dessas preocupações, insere-se a necessidade de estudos concernentes à formação do professor da escola do campo, pois não é possível mais se pensar em educação desvinculada da realidade de seus atores, de suas práticas. Daí a importância do recorte da linha de pesquisa "Prática Pedagógica" nos TCCs, como forma de investigação e conhecimento com mais propriedade da prática desenvolvida por esses professores.

\subsection{QUANTITATIVOS DE ALUNOS NAS LINHAS DE PESQUISA}

O Curso de Especialização em Educação do Campo foi ofertado em 19 municípios do estado do Maranhão, abrangendo um total de 820 alunos aptos às orientações. Todavia, somente 728 tiveram os seus artigos concluídos e inseridos no AVA, dos quais, 306 artigos faziam parte da linha de pesquisa "Prática Pedagógica", o que representa 42\% do total analisado, percentual bastante significativo para o contexto da pesquisa em apreço.

No que diz respeito às orientações dos artigos, procedeu-se à distribuição dos professores orientadores na seguinte proporção: cada tutor ficou, em média, com 10 a 15 alunos e iniciou as atividades apresentando as linhas de pesquisas e o que tratava cada uma. Essas ações foram imprescindíveis no processo de orientação dos mesmos. 
Gráfico 1: Demonstrativo dos Artigos por Linha de Pesquisa

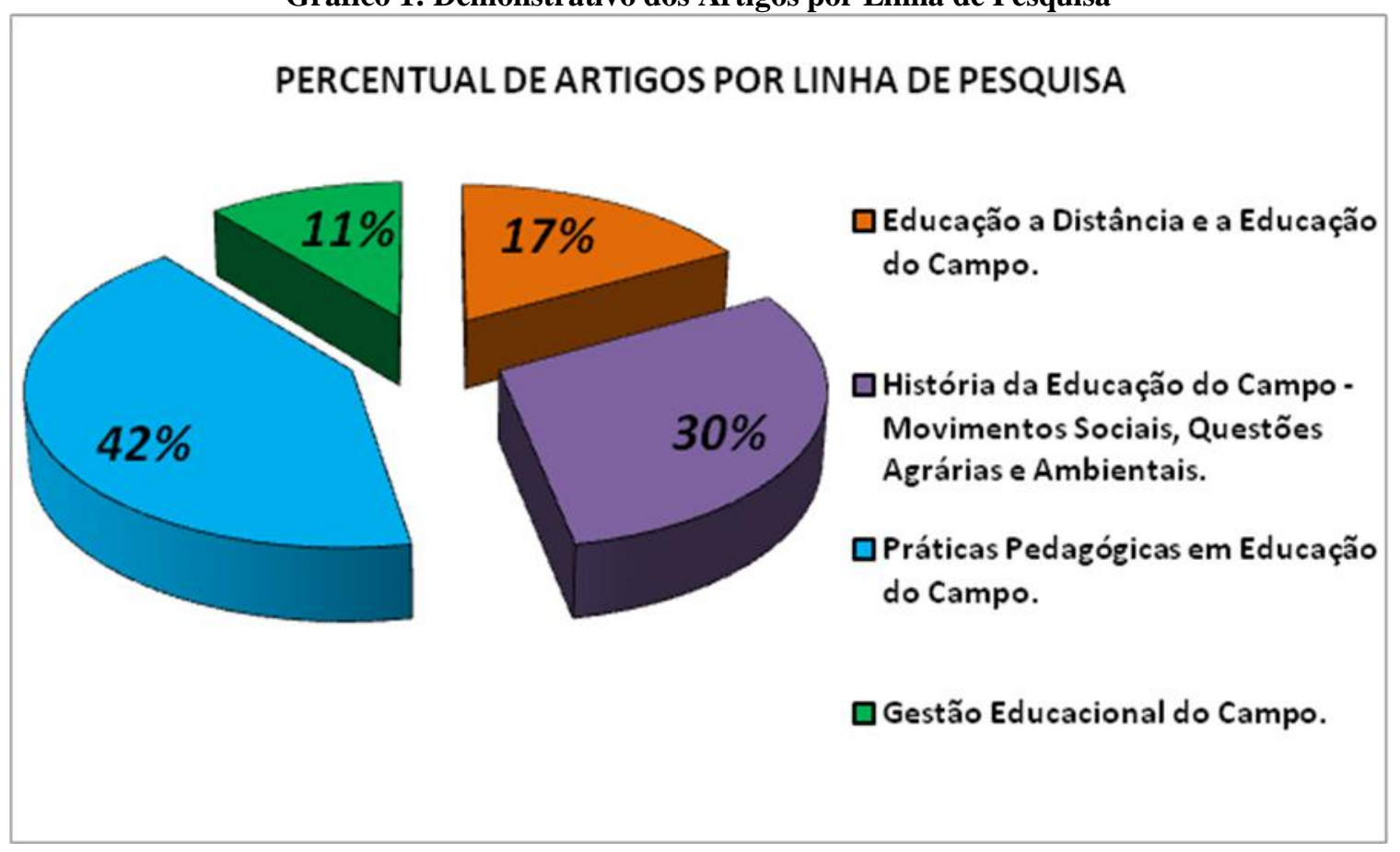

Com a base teórica oferecida pelo curso, cujas abordagens estavam focadas na prática pedagógica do campo, 42\% dos alunos apresentaram trabalhos na linha de pesquisa "Práticas Pedagógicas". Assim, os conteúdos estudados nos módulos do curso encontravam-se articulados à experiência dos estudantes. Estabelecer elos entre os conteúdos e a vida prática significa a possibilidade de exercitar vivências significativas, "permitindo aos sujeitos refletir sobre suas realidades e assim compreendê-las". SILVA (2009, p.88).

Ainda nos fóruns e discussões das disciplinas disponibilizadas no AVA, as questões práticas do cotidiano do professor eram compartilhadas nos grupos de trabalho. A maioria dos artigos elaborados adotou a metodologia da pesquisa participante, onde o sujeito pesquisador interfere participativamente para as melhorias dos espaços de aprendizagem no campo, conforme aborda Brandão e Borges (2007, p.54):

Deve-se partir da realidade concreta da vida cotidiana dos próprios participantes individuais e coletivos do processo, em suas diferentes dimensões e interações - a vida real, as experiências reais, as interpretações dadas a estas vidas e experiências tais como são vividas e pensadas pelas pessoas com quem inter-atuamos.

Constatou-se, ainda na pesquisa, que os alunos que não trabalham em sala de aula desenvolveram artigos nas outras linhas de pesquisa, a saber: $30 \%$ trabalharam na linha de pesquisa "História da Educação do Campo, Movimentos Sociais, Questão Agrária e Ambiental”. Esses indicadores mostram que esses cursistas trabalharam seus artigos em consonância com as questões do 
campo, mesmo não sendo professores, demonstrando, dessa forma, preocupação com as questões campestres, bem como em contribuir com os eixos temáticos do curso.

Para Pereira (2000), a prática se constitui o eixo dessa preparação, sendo que, por essa via, o contato com a experiência docente deve acontecer desde o início da formação. A partir da prática surgem os elementos que devem ser postos em discussão no contexto das disciplinas teóricas, "vez que no processo de formação teoria e prática não se apresentam mais dissociadas, mas articuladas ao mesmo tempo". (PEREIRA, 2000, p.113).

Nesse contexto, a aprendizagem se renova e se amplia sob o comando da experiência, ou seja, à luz dos desafios concretos com que o docente se depara no cotidiano de sua prática. Os estudos de Zabala indicam que a prática educativa se concretiza por meio de diversas variáveis que se interrelacionam de forma complexa e se expressa no micro sistema da sala de aula. Assim coloca o autor:

\begin{abstract}
Sabemos muito pouco, sem dúvida, sobre os processos de ensino-aprendizagem, das variáveis que intervêm neles e de como se inter-relacionam. Os próprios efeitos educativos dependem da interação complexa de todos os fatores que se inter-relacionam nas situações de ensino: tipo de atividade metodológica, aspectos materiais da situação, estilo do professor, relações sociais, conteúdos culturais etc. (ZABALA, 1998, p. 15).
\end{abstract}

\title{
5 CONSIDERAÇÕES FINAIS
}

O Curso de Especialização em Educação do Campo a distância contribuiu para um conjunto de saberes voltados à realidade e especificidade dos sujeitos do campo. Os resultados dos estudos revelaram que os objetivos esperados foram alcançados, pois os Trabalhos de Conclusão de Curso demonstraram senso crítico nas pesquisas realizadas.

$\mathrm{Na}$ visão dos professores, o curso significou um espaço para o aprendizado e lhes proporcionou maior embasamento científico, especialmente, no que concerne à prática pedagógica, no qual tiveram a oportunidade de aprofundamento por meio da pesquisa que culminou com a produção dos artigos. Isso vem ao encontro do pensamento de Moreira, cujo entendimento é de que o ambiente de aprendizagem escolar se constitui um lugar previamente organizado para promover oportunidades de aprendizagem, constituindo-se, dessa forma, possibilidade única na medida em que é socialmente construído por alunos e professores a partir das interações que estabelecem entre si e com as demais fontes materiais e simbólicas do ambiente. (MOREIRA, 2007)

Por conseguinte, compreende-se que as aprendizagens dependem das características individuais, da forma como se aprende e do ritmo da aprendizagem que varia segundo as capacidades de cada um. Foi nesse sentido que o Curso de Especialização em Educação do Campo, na modalidade a distância, oportunizou aos alunos-professores a obtenção de saberes mais específicos da realidade do campo. 
Assim, a maneira como se produzem as aprendizagens é o resultado de processos singulares e pessoais. A identificação das fases de uma sequência didática deve servir para compreender o valor educacional que elas têm, as razões que as justificam e a necessidade de introduzir mudanças ou atividades que as melhorem. Essas transformações foram abordadas no ato da apresentação dos artigos, onde os alunos tiveram a oportunidade de externar que o aprendizado teve relevância pessoal e coletiva, vez que foi extensiva à sua comunidade, na medida em que os estudos já foram intervindo na realidade.

Todavia, observou-se que 92 alunos sentiram dificuldades em elaborar o artigo como TCC, notadamente, em função das dificuldades relativas ao manuseio com computador, à experiência com pesquisa e, ainda, à ausência de material bibliográfico nos municípios, o que, de certa forma, causou desmotivação aos cursistas, resultando na desistência do trabalho final, ficando, pois, sem concluírem o curso.

Essas questões remetem a reflexões sobre a necessidade de se resolverem as dificuldades apresentadas neste estudo, especialmente, no que diz respeito aos alunos/professores, para que possam ter melhor aproveitamento nos cursos e venham elaborar projetos que contribuam com a comunidade em que vivem, pois os mesmos precisam conhecer melhor os movimentos sociais, as questões agrárias e o planejamento para a gestão da Educação do Campo, elementos necessários à melhoria do processo do ensino e à valorização das histórias dos próprios povos campesinos.

Concluiu-se, então, que os artigos produzidos pelos alunos são de total relevância para as comunidades acadêmicas e locais, pois socializa o que foi produzido e possibilita a reconstrução dos espaços de relação que fortalecem as raízes do povo do campo, bem como aproxima a cultura com a realidade da comunidade. Ressalta-se, aí, a linha de pesquisa "Práticas Pedagógicas", cujas contribuições são de grande significância para as escolas do campo no sentido de que os artigos trazem consideráveis contribuições para o cotidiano escolar. 


\section{REFERÊNCIAS}

ANDRADE, E. M. de. As práticas pedagógicas do tutor na educação a distância. In :Anais do IX Seminário Pedagogia em Debate e IV Colóquio Nacional de Formação de Professores. Curitiba: Universidade Tuiuti do Paraná, 2009.

ARAUJO, Eliza Flora Muniz. A Prática Educativa nas Classes Multisseriadas: impasses e desafios. (Dissertação de Mestrado). Funchal - Pt: Universidade da Madeira, 2010. Disponível em: < http://digituma.uma.pt/bitstream/10400.13/131/1/MestradoElizaAra\%C3\%BAjo.pdf >. Acesso em: 7 mai. 2014.

BRANDÃO, Carlos Rodrigues e BORGES, Maristela Correa. A pesquisa participante: um momento da educação popular. In: Revista Educação Popular, Uberlândia, v. 6, p.51-62. jan./dez. 2007. Disponível em: < http://www.seer.ufu.br/index.php/reveducpop/article/view/19988/10662 >. Acesso em: 13 jun.2014.

BRASIL, Ministério da Educacão.Propostas de Diretrizes para a Formação Inicial de Professores da Educação Básica, em Cursos de Nível Superior. Brasília, Abril de 2001.

CONFERÊNCIA NACIONAL DE EDUCAÇÃO (CONAE), 2010, Brasília, DF. Construindo o Sistema Nacional Articulado de Educação: o Plano Nacional de Educação, diretrizes e estratégias; Documento Final. Brasília, DF: MEC, 2010. Disponível em:http://Conae.mec.gov.br/images/stories/pdf/pdf/doc_base_documento_final.pdf $>$. Acesso em: 7 mai. 2014.

SACRISTÁN, Gimeno J. Consciência e ação sobre a Prática como Libertação Profissional dos Professores, In Novoa, A. (org.) Profissão Professor. 2. ed. Lisboa, Porto Editora, 1999.

SOARES, Edla de Araújo Lira. Diretrizes Operacionais para a Educação Básica nas Escolas do Campo. Parecer n. ${ }^{\circ}$ 36/2001. Edla de Araújo Lira Soares (Relatora). Câmara de Educação Básica do Conselho Nacional de Educação. Brasília, 2001.

KOLLING, Edgar Jorge; NÉRY, Irmão e MOLINA, Mônica Castanha. Por uma educação básica do campo (Memória). Brasília/DF: Fundação Universidade de Brasília, 1999.

FORMIGA, Manuel Marcos Maciel; LITTO, Fredric Michael. Educação a distância: o estado da arte. São Paulo: Pearson Educatio do Brasil, 2009.

HARASIM, Linda. Redes de aprendizagem: um guia para ensino e aprendizagem on- line. São Paulo: Editora Senac, 2005.

MINAYO, Maria Cecília de Souza. (org.). Pesquisa social. Teoria, método e criatividade. 25. ed. rev. atual. Petrópolis: Vozes, 2007.

. Trabalho de Campo: Contexto de Observação, Interação e Descoberta. In: Pesquisa Social: teoria, método e criatividade. Suely Ferreira Deslandes; Maria Cecília de Souza Minayo (org.). 27 ed. Petrópolis: Vozes, 2008.

MOREIRA, Adelson F. Ambientes de Aprendizagem no Ensino de Ciência e Tecnologia. Belo Horizonte: CEFET-MG, 2007. 
PEREIRA, J. E. D. Formação de professores: pesquisa, representações e poder. Belo Horizonte: Autêntica, 2000. (Coleção Trajetória, 4).

PIMENTA, Selma G. (orgs). Professor reflexivo no Brasil: gênese e crítica de um conceito. 4. ed. São Paulo: Cortez, 2002.

SILVA, Jaqueline Luzia da. Letramento: uma prática em busca da (re) leitura do mundo. Rio de Janeiro: Wak Ed., 2009.

TARDIF, M. Saberes profissionais dos professores e conhecimentos universitários:

elementos para uma epistemologia da prática profissional dos professores e suas consequências em relação a formação para o magistério. Revista Brasileira de Educação. jan - abr., n. 13, 2000.

VÁSQUEZ, A. S. Filosofia da práxis. Rio de Janeiro: Paz e Terra, 1977.

VIGEVANI, T. Pensar a crise na Universidade para além das questões conjunturais. In: LOUREIRO, I, DEL- MASSO, M. C. (orgs.) Tempos de greve na Universidade Pública. Marília: UNESP Marília Publicações, 2001.

ZABALA, Antoni. A prática educativa: como ensinar. Porto Alegre: Artmed, 1998. 